\title{
Estimation of betas of stocks with low liquidity
}

\author{
Ricardo Goulart Serra ${ }^{\dagger}$ \\ Insper / IBMEC-SP and FIA \\ Roy Martelanc ${ }^{\Omega}$ \\ University of São Paulo
}

\begin{abstract}
This paper examines the procedure to estimate betas for firms whose shares are not traded every day. Betas are estimated by three methods: repetition of the last quotation (RUC), tradeto-trade (TT) and Scholes-Williams' adjustment (SW). There are three return intervals: daily, weekly and monthly. The objective is to verify the consistency of the betas estimated by the different calculation methods and the different return intervals. The results indicate that for shares not traded every day, the betas could be estimated with better precision by the TT method with daily intervals.
\end{abstract}

Keywords: Beta; illiquid stocks; repetition of the last quotation; trade-to-trade; Scholes and Williams; capital market.

${ }^{t}$. PhD from the University of São Paulo Affiliation: Professor of finance at Insper/ IBMEC-SP and FIA.

Address: Rua do Roccio, 109, $6^{\circ}$ andar, São Paulo

- SP - Brasil

E-mail: Ricardo.serra@usp.br

Telephone: (11)3818-4020

\footnotetext{
${ }^{\Omega} \mathrm{PhD}$ from the University of São Paulo. Affiliation: Professor of finance at the University of São Paulo (FEA/USP). Address: Av. Professor Luciano Gualberto, 908, Cidade Universitária, São Paulo - SP$$
\text { - Brasil }
$$

E-mail: rmartela@usp.br

Telephone: (11)3847-3708
} 


\section{INTRODUCTION}

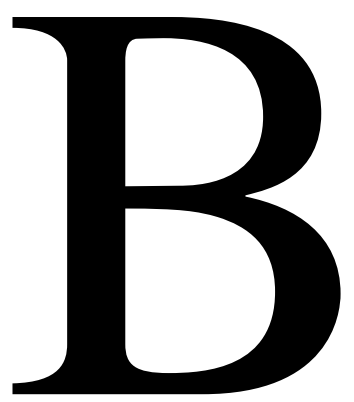

eta is one of the essential parameters in finance. It is used in the estimation of the expected stock return, with four main applications. The first is the estimation of the cost of equity, the cost of the capital and, consequently, the investment decision. The second is the investment decision in an asset portfolio, especially stocks. The third is the estimation of the expected returns in academic studies, like the innumerable tests of the market efficiency hypothesis. The fourth is the definition of public service tariffs (Bodie, Kane and Marcus, 2000: 224). The lack of precision in the calculation of beta can

lead to incorrect cost of equity estimates (applying the inadequate beta) and consequently to incorrect decisions or conclusions.

A stock's beta is commonly calculated by regression between its return and that of a market portfolio, at first both discounted by the return of a risk free asset.

During the beta estimation, one can face, many times, the problem of the stock's low liquidity. There may be days when the stock is not traded, therefore there is no information about its return; other days with a low business volume, in which the stock's price and return, is hardly representative of what would have occurred if the liquidity were adequate. There can also occur days with a reasonable total volume, but a low volume at the end of the day, which is when the closing prices are determined and the market return is calculated.

The objective of the paper is to discover which of the methods and return periodicities tested provide robust beta estimations in series that have days without trading. The tested methods are those of the repetition of the last quote (RUC method), of the trade-to-trade (TT method) and the adjustment proposed by Scholes and Williams (1977) (SW method). The tested return periodicities are daily, weekly and monthly.

To meet this objective, a simulated computer quasi-experiment was used, in which the betas of incomplete price series are estimated with several procedures and compared with the underlying beta that generated the simulated data.

According to the results obtained, it can be said that, to calculate the beta of stocks with low liquidity, the best alternative is the TT method with daily periodicity.

This paper is made up of five sections, including the current section: the introduction. The second section presents the conceptual review about the beta and the main parameters for its calculation. The subsequent section presents the approaches to calculate the beta os stocks 
with low liquidity and the methodology employed in the simulation. The fourth section discusses the results obtained. The last section presents the final considerations.

\section{CONCEPTUAL REVIEW}

The literature (Koller, Goedhart and Wessels, 2002; Damodaran, 1994) raises 3 main methodological decisions for the beta's estimation: (i) market index (local or international), (ii) return history (2, 3 or 5 years) and (iii) return periodicity (daily, weekly or monthly).

\subsection{Market Index}

As regards the market index, the common practice is to use the market index in which the company's stock is negotiated, although the international investor will be far better served if an international index is used (Damodaran, 1994). Koller et. al. (2002) suggest the MSCI World and S\&P indices. Copeland, Koller and Murin (2002: 374) also indicate the use of a global index as ideal, however, as they consider that global indices are relatively recent, they fall back on the index of the United States market (S\&P 500).

\subsection{Return History}

As for the return history, the larger the number of observations, the greater the precision and the smaller the error in the beta estimate, which would be favored by a long history of returns. However, when the collection period increases, there is also an increase in the probability that the company has suffered structural changes during the period being considered, which would result in a change of the beta. Daves, Ehrhardt and Kunkel (2000) believe that less than $50 \%$ of companies suffer significant beta changes in less than 3 years, for which reason they recommend the use of a history smaller than 3 years. Damodaran (1994) comments that the Value Line and Standard and Poor's databases use a 5-year history, while the Bloomberg database uses a 2-year history. Kooler et. al. (2002) suggest the use of 60 monthly observations, which is equal to a history of 5 years.

Following the guidance of Davis et. al. (2000), it was decided to use a 3-year history of returns in the paper, having in view that the monthly periodicity, among other possibilities, will be used. A history shorter than 3 years would lead to an estimation of monthly betas with less than 36 observations.

\subsection{Periodicity of Returns}

As regards the periodicity of returns, there is also no consensus. 
Daves et. al. (2000) are of the opinion that a daily return periodicity should be used, for this produces a lower standard error in the estimation of betas. They state that most recent studies have used the daily beta and recommend that financial administrators choose this periodicity.

The beta of companies that are not traded every day is biased downwards according to Dimson (1979). It is observed that the problem of the non-synchronism between the market data and the action data is especially serious when daily data is used (Scholes and Williams, 1977). Given that smaller periodicities can bias the beta of companies whose stock is not traded every day, Damodaran (1994) and Kooler et. al. (2002) recommend the use of the monthly periodicity.

Copeland, Weston and Shastri (2005: 167) comment that most studies testing the CAPM use monthly periodicity, listing studies from 1970 to 1995 . Until 1970, the tests were made from monthly series, since daily series did not exist, which were made available during the mid-1970s.

As the beta is calculated dividing (i) the covariance between the market return and the stock return by (ii) the market variance (eq. 1), and the covariance of a stock that is not traded every day is biased downwards, the calculated beta is, therefore, biased downwards.

$$
\beta=\frac{\mathrm{COV}_{\text {jm- }}}{\mathrm{VAR}_{\mathrm{m}}}
$$

In which $\mathrm{COV}_{\mathrm{jm}}$ is the covariance between the market return and the stock return $\mathrm{j}$ and $\mathrm{VAR}_{\mathrm{m}}$ is the market variance.

Handa, Kothari and Wasley (1989: 98-99) also demonstrate that the periodicity of returns influences the beta, for the covariance of the returns does not vary proportionally to the market variance with the different return intervals. In their words: "Beta's of high-risk securities increase with the return interval, whereas beta's of low-risk securities decrease with the return interval". The authors also suggest the use of annual periods.

It is also noteworthy that, for the same set of data, betas estimated using daily periodicity can be different from betas estimated using monthly periodicity. "Securities with a smaller market value than the average of all securities outstanding (the market) will generally 
have a decreasing beta, whereas securities with a larger market value than the average of all securities outstanding will generally have an increasing beta" (Hawawini, 1983: 73).

In this paper, three periodicities will be used: daily, weekly and monthly.

\section{METHODOLOGY}

\subsection{Procedures for the estimation of the beta}

The beta of an asset can be estimated by regressing the return of the asset against the return of a market portfolio, as in eq. 2 or its variant of eq. 3.

$$
\begin{gathered}
\mathrm{R}_{\mathrm{jt}}=\mathrm{R}_{\mathrm{ft}}+\beta_{\mathrm{j}}\left(\mathrm{R}_{\mathrm{mt}}-\mathrm{R}_{\mathrm{ft}}\right)+\varepsilon_{\mathrm{jt}} \\
\mathrm{R}_{\mathrm{jt}}=\alpha_{\mathrm{j}}+\beta_{\mathrm{j}} \mathrm{R}_{\mathrm{mt}}+\varepsilon_{\mathrm{jt}}
\end{gathered}
$$

In which $R_{j t}$ is the return of stock $j$ during period $t, R_{f t}$ is the risk free return in period $t$, $R_{m t}$ is the return of the market index during period $t, \alpha_{j}$ is the intercept of stock $j, \beta_{j}$ is the beta of stock $\mathrm{j}$ and $\varepsilon_{\mathrm{jt}}$ is the error of stock $\mathrm{j}$ in period t. Observe that the difference between the models is in the fact that the risk free return depends on $t$ in the model of eq. 2 and the intercept being constant in the model of eq. 3 .

It is common to operationalize this regression for stocks with low liquidity by means of the Repetition of the Last Quote (RUC Method). There are at least two alternative approaches to calculate the stock betas that are not traded every day: (a) calculate the regression using the stock return interval, called "trade-to-trade", from the marriage of the stock return - between dates when there has been a negotiation - and the return of the market index during the same period (Marsh, 1979 and Dimson and Marsh, 1983); and (b) introduce the return of the market index lagged and advanced as additional independent variables (Scholes and Williams, 1977, Dimson, 1979 and Cohen, Hawawini, Maier, Schwarz and Whitcomb, 1983).

In this paper, beside the repeat of last quote method (RUC), the trade-to-trade method (TT) and the Scholes and Williams (SW) adjustment methods will be used.

\subsubsection{Repetition of Last Quote Method (RUC Method)}

The repetition of last quote method (RUC) is provided by the Bloomberg ${ }^{\circledR}$ and Reuters ${ }^{\circledR}$ databases and is one of the methods made available by Economática ${ }^{\circledR}$. Observe that Reuters calculates the beta only for a monthly return interval, Bloomberg initially suggests the weekly beta (which can be changed by the user) and Economática suggests initially the monthly beta 
(which can be changed by the user). Economática, as a default, does not calculate the beta for stocks that does not present at least $70 \%$ of trading days in the used history.

In calculating the beta for the companies whose stocks are not traded every day, a price may have to be attributed to a stock on a date in which the company stock was not traded. In these cases, one possibility is to attribute, for the date when the company's stock was not traded, the price of the last day it has been traded. In this manner, through this method, the beta calculation uses prices on days when the company stock wasn't traded, which generates a mismatch between the stock price and the market index quote. Using these periods when there was no trading of the stock in regression reduces the stock's return variance and the correlation between the return of the stock and the return of the market. Consequently, beta (Damodaran, 1997, p. 133) also falls. Therefore, the RUC method can bias downwards the estimated betas of stocks with low liquidity.

The operational procedure of the RUC method is described below:

- Starting with the reference date, the return history and the return interval, a series of dates are obtained.

- For each date of this series of dates, the index quote and the price of the stock at issue are obtained.

- The stock price on a specific date is the price of the date itself, if it has been traded on that date, or if it wasn't traded on that date, the price of the last date in which it was traded.

- With these two series of quotes, a return series of the index and a return series of the stock are calculated and, later, the stock's beta is calculated.

\subsubsection{Trade-to-Trade Method (TT Method)}

Marsh (1979), in a study of events, used the "trade-to-trade" method (TT) to calculate the beta of stocks with low liquidity. In this approach, the stock's return must have regressed against the return of the market on synchronized dates. To correct a potential problem of heteroscedasticity in the error component, Dimson and Marsh (1983: 756) propose an estimator to improve its efficiency. In this paper, the last proposal was not used. Maynes and Rumsey (1993) also indicate the use of trade-to-trade for event studies with stocks that are not traded every day. 
The TT method, therefore, uses stock prices only on the dates when the stock was actually traded. In this manner, there is no mismatch between the share price and the market index price, since both are on dates on which the company's stock was traded. On the other hand, the intervals between the quotes are no longer exactly the same.

The operational procedure adopted in this paper for the TT method is:

- Starting with the reference date, the return history and the return interval, a series of dates are obtained.

- The date considered in the series of dates is the date itself, if the stock in question has been traded on that date, or the date immediately previous to it in which the stock in question was traded.

- If the date immediately previous in which the stock in question has been traded is at a distance from the original date that is beyond the return interval, this date will be eliminated from the series of dates.

- For each date of the series of dates, the index quote and the price of the stock are obtained. Observe that the new date will serve to obtain the price of the stock and also to obtain the quote of the market index. In this manner, only the dates when the stock was traded are considered. One supposes that the index trades every day, which is the case of Ibovespa.

- With these two series of quotes, a return series of the index and a return series of the stock are calculated and, later, the stock's beta is calculated.

\subsubsection{Scholes e Williams Approach (1977) (SW Method)}

Scholes and Williams' approach (1977) involves 3 estimates of the single factor model, to later calculate the beta, considering the results of these 3 estimates, according to eq. 4 :

$$
\begin{gathered}
\mathrm{R}_{\mathrm{i}, \mathrm{t}}=\alpha_{-1 \mathrm{i}}+\beta_{-1 \mathrm{i}} * \mathrm{R}_{\mathrm{m}, \mathrm{t}-1}+\varepsilon_{-1 \mathrm{i}, \mathrm{t}} \\
\mathrm{R}_{\mathrm{i}, \mathrm{t}}=\alpha_{0 \mathrm{i}}+\beta_{0 \mathrm{i}} * \mathrm{R}_{\mathrm{m}, \mathrm{t}}+\varepsilon_{0 \mathrm{i}, \mathrm{t}} \\
\mathrm{R}_{\mathrm{i}, \mathrm{t}}=\alpha_{+1 \mathrm{i}}+\beta_{+1 \mathrm{i}} * \mathrm{R}_{\mathrm{m}, \mathrm{t}+1}+\varepsilon_{+1 \mathrm{i}, \mathrm{t}} \\
\beta_{\mathrm{SW}}=\frac{\beta_{-1 \mathrm{i}}+\beta_{0 \mathrm{i}}+\beta_{+1 \mathrm{i}}}{1+2 \times \rho_{\mathrm{M}}}
\end{gathered}
$$


In which, $R_{i, t}$ is the return of stock $i$ in period $t, R_{m, t+z}$ is the return of the market index during period $\mathrm{t}+\mathrm{z}, \alpha_{\mathrm{zi}}$ is the intercept associate to the return of the market index during period $\mathrm{t}+\mathrm{z}, \beta_{\mathrm{zi}}$ is the beta of stock $\mathrm{i}$ associated with the return in the market index during period $\mathrm{t}+\mathrm{z}$, $\varepsilon_{\mathrm{zi}, t}$ is the term of error associated to the return of the market index in period $\mathrm{t}+\mathrm{z}$ and $\rho_{\mathrm{M}}$ is the correlation between the market return series and the delayed series one period behind the market return.

Besides the Scholes and Williams approach (1977), the literature presents Dimson approach (1979), which involved the estimation of a multiple regression. In it, beta is calculated based on the beta coefficients of a multiple regression, according to eq. 5 :

$$
\begin{gathered}
\mathrm{R}_{\mathrm{i}, \mathrm{t}}=\alpha_{\mathrm{i}}+\beta_{-1 \mathrm{i}} * \mathrm{R}_{\mathrm{m}, \mathrm{t}-1}+\beta_{0 \mathrm{i}} * \mathrm{R}_{\mathrm{m}, \mathrm{t}}+\beta_{+1 \mathrm{i}} * \mathrm{R}_{\mathrm{m}, \mathrm{t}+1}+\varepsilon_{\mathrm{i}, \mathrm{t}} \\
\beta_{\mathrm{DIM}}=\beta_{-1 \mathrm{i}}+\beta_{0 \mathrm{i}}+\beta_{+1 \mathrm{i}}
\end{gathered}
$$

In which, $R_{i, t}$ is the return of stock $i$ in period $t, R_{m, t+z}$ is the return of the market index in period $\mathrm{t}+\mathrm{z}, \alpha_{\mathrm{i}}$ is the intercept, $\beta_{\mathrm{zi}}$ is the beta of stock $\mathrm{i}$ associated with the return of the market index in period $\mathrm{t}+\mathrm{z}$ and $\varepsilon_{\mathrm{i}, \mathrm{t}}$ is the error of stock $\mathrm{i}$ in period $\mathrm{t}$. In cases when there are more days without trading, the number of lagged and advanced terms will increase.

Fowler and Rorke (1983: 282) show that Dimson's estimator "is inconsistent with Scholes and Williams' and, therefore, incorrect." Cohen et. al. (1983) also point out a small inconsistency in Dimson's derivation and propose a revised estimator, not used in this paper.

Bartholdy and Riding (1994: 242 and 243) indicate that the procedures of Scholes and Williams (1977) and Dimson (1977) are widely used in the literature and that Marsh's procedure (1979) is rarely used.

\subsection{Simulation}

The greatest problem encountered to study companies' betas is that the same is not actually known. In a simulation, the true beta (underlying beta) is known a priori and can be compared to the beta estimated by various methods.

In this quasi-experiment, considering controlled variables and distributions, without the interference of environmental noises, there is the possibility of observing the pure impact of a variable:

Real data is messy, and no one really knows all of the features that lurk inside it (...) By contrast, simulation is the econometrician's chance to behave like a real scientist, conducting experiments under controlled conditions. (Brooks, 2001: 547) 
Dimson (1979) simulated data according to eq. 3, Bowie and Bradfield (1993) simulated data according to eq. 6 , and this paper simulated data according to eq. 2 .

$$
\mathrm{R}_{\mathrm{jt}}=\mathrm{R}_{\mathrm{mt}}+\varepsilon_{\mathrm{jt}}
$$

In this manner, it can be constructed from a random error for the market, a random series of returns for the market, and from this, together with an underlying beta and a random error for the asset, it can be constructed a random series of returns for an asset.

To obtain the random series, the following general premises are considered, consistent with the general parameters of the financial market:

- Risk-free rate $\left(\mathrm{R}_{\mathrm{f}}\right): 0.0238 \%$ p.d., equivalent to a premise of $6.0 \%$ p.a.. It was decided to keep the risk-free rate constant due to its low variability in comparison with the variability of the return of the market and the stock.

- The Market Premium $\left(\mathrm{R}_{\mathrm{m}}-\mathrm{R}_{\mathrm{f}}\right): 0.0198 \%$ p.d., is equivalent to a premise of $5.0 \%$ p.a..

- Random error for the market $\left(\varepsilon_{\mathrm{m}}\right)$ : with normal distribution, zero mean and standard deviation $\sigma_{\varepsilon m}$ of $1.6 \%$ p.d., consistent with the Ibovespa standard deviation during the $31 / 12 / 2004$ to $31 / 12 / 2007$ period. As an alternative, the $t$ distribution with 10 degrees of freedom was simulated, to consider the market characteristic of presenting distributions with broad tails.

- $\quad$ Beta of the stock $\left(\beta_{\mathrm{j}}\right)$ : three scenarios, $0.75,1.00$ and 1.25 .

- Random error for the asset $\left(\varepsilon_{\mathrm{jt}}\right)$ : with normal distribution, zero mean and standard deviation $\sigma_{\varepsilon j}$ of $2.5 \%$ p.d. The standard deviation used is consistent with the mean standard deviation of the difference between the stock return and the expected stock return (calculated as $\beta_{\mathrm{i}} * \mathrm{Rm}_{\mathrm{t}}$ ) calculated for several stocks during the period between $31 / 12 / 2004$ and $31 / 12 / 2007$, in which $\beta_{i}$ is the beta of asset $i$ calculated for a return period of 3 years and monthly periodicity. As an alternative, the t distribution with 10 degrees of freedom was simulated, to consider the market characteristic of presenting distributions with broad tails.

Based on a random series of daily return of a stock, a series of prices was calculated, from which were calculated series of prices for 4 different scenarios of days with trading: $60 \%, 70 \%, 80 \%$ and $90 \%$, considering that the original series is already the series with $100 \%$ of days with trading. Taking, for example, the scenario with $70 \%$, for each day of the data 
series, a random number was generated with a $70 \%$ probability of being 1 (corresponding to the stock being traded that day) and $30 \%$ probability of being 0 (corresponding to the stock not being traded that day). For days when the stock is traded, its price was taken from the original series, and for the days when the stock isn't traded, its price from the original series was ignored. Therefore a series of prices was obtained for the stock with the $70 \%$ of days of negotiation, to which were applied each one of the methods (RUC, TT and SW) and the tested periodicities (daily, weekly and monthly).

For each of the 15 scenarios ( 3 levels of betas and 5 levels of trading days), 10,000 series of three years of quotes for the market index and their corresponding quotes for the stock were generated. These 10,000 series of pairs of quotes were then submitted to the beta calculation according to three methods (RUC, TT and SW) and the three periodicities tested (daily, weekly and monthly).

\subsection{Statistical Approach}

The null hypothesis $-\mathrm{H}_{0}$ - of the hypothesis test for the current paper is that the average of the estimated betas is equal to the underlying beta, that is:

$$
\mathrm{H}_{0}: \beta_{\text {estimated }}=\beta_{\text {underlying }}
$$

The complementary alternative hypothesis $-\mathrm{H}_{\mathrm{a}}-$ is that the average of the estimated betas according to the different methods and premises are different, that is:

$$
\mathrm{H}_{\mathrm{a}}: \beta_{\text {estimated }} \neq \beta_{\text {underlying }}
$$

The hypothesis will be tested, expecting not to reject $\mathrm{H}_{0}$ for the 135 combinations of:

- beta levels: $0.75 ; 1.00$ and 1.25 ;

- levels of trading days (liquidity): 60\%, 70\%, 80\%, $90 \%$ and $100 \%$;

- method: TT, RUC and SW; and

- periodicity: daily, weekly and monthly.

Each combination was tested with a simulation of 10,000 cases.

\section{DATA ANALYSIS}

\subsection{Analysis of the estimated in relation to the underlying beta}

For each one of the 135 possible combinations ( 3 levels of beta x 5 levels of liquidity $\mathrm{x}$ 3 methods x 3 periodicities) 10,000 betas were estimated, for which (a) were calculated: the average, the standard deviation and the coefficient of variation (standard deviation/average); 
and (b) those averages which are different from the underlying beta were highlighted, with a significance of $1 \%$. Also, a confidence interval for each beta was built, individually calculated with $1 \%$ of significance to verify if this confidence interval (C.I.) would contain the underlying beta. This last analysis was carried out by the RUC and TT methods. These results are present in table 1.

\section{Table 1 - Analysis of Estimated Betas}

Panel (a): Underlying beta 0.75

\begin{tabular}{|c|c|c|c|c|c|c|c|c|c|c|}
\hline & & \multirow{2}{*}{\multicolumn{3}{|c|}{ Trade-to-Trade }} & \multirow{2}{*}{\multicolumn{3}{|c|}{ Repetition of Last Quote }} & \multirow{2}{*}{\multicolumn{3}{|c|}{ Scholes and Williams }} \\
\hline & & & & & & & & & & \\
\hline & & Daily & Weekly & Monthly & Daily & Weekly & Monthly & Daily & Weekly & Monthly \\
\hline \multirow{4}{*}{$60 \%$} & average & 0.750 & 0.752 & 0.744 & $0.450 *$ & $0.652 *$ & $0.718 *$ & $0.630^{*}$ & 0.747 & 0.815 \\
\hline & standard & 0.087 & 0.134 & 0.276 & 0.064 & 0.134 & 0.278 & 0.105 & 0.232 & 5.631 \\
\hline & $\begin{array}{l}\text { deviation } \\
\text { coefficient of } \\
\text { variation }\end{array}$ & 0.116 & 0.178 & 0.371 & 0.142 & 0.206 & 0.387 & 0.167 & 0.311 & 6.909 \\
\hline & $\%$ cases in C.I. & $97.0 \%$ & $96.3 \%$ & $98.9 \%$ & $1.5 \%$ & $98.7 \%$ & $99.0 \%$ & n.a. & n.a. & n.a. \\
\hline \multirow{4}{*}{$70 \%$} & average & 0.750 & 0.751 & 0.746 & $0.526^{*}$ & $0.686^{*}$ & $0.731 *$ & $0.683^{*}$ & 0.747 & 0.826 \\
\hline & standard & 0.077 & 0.131 & 0.275 & 0.062 & 0.131 & 0.277 & 0.102 & 0.232 & 7.299 \\
\hline & $\begin{array}{l}\text { deviation } \\
\text { coefficient of } \\
\text { variation }\end{array}$ & 0.103 & 0.174 & 0.369 & 0.118 & 0.191 & 0.379 & 0.149 & 0.311 & 8.837 \\
\hline & $\%$ cases in C.I. & $97.8 \%$ & $97.9 \%$ & $99.0 \%$ & $13.8 \%$ & $98.6 \%$ & $98.9 \%$ & n.a. & n.a. & n.a. \\
\hline \multirow{4}{*}{$80 \%$} & average & 0.751 & 0.750 & 0.745 & $0.601 *$ & $0.713 *$ & $0.735^{*}$ & $0.720^{*}$ & 0.747 & 0.797 \\
\hline & standard & 0.069 & 0.131 & 0.276 & 0.061 & 0.131 & 0.277 & 0.101 & 0.230 & 4.173 \\
\hline & $\begin{array}{l}\text { deviation } \\
\text { coefficient of } \\
\text { variation }\end{array}$ & 0.092 & 0.175 & 0.370 & 0.101 & 0.184 & 0.377 & 0.140 & 0.308 & 5.236 \\
\hline & $\%$ cases in C.I. & $98.1 \%$ & $98.6 \%$ & $98.9 \%$ & $52.0 \%$ & $99.0 \%$ & $99.0 \%$ & n.a. & n.a. & n.a. \\
\hline \multirow{4}{*}{$90 \%$} & average & 0,750 & 0.751 & 0.745 & $0.675^{*}$ & $0.735^{*}$ & $0.741 *$ & $0.743 *$ & 0.747 & 0.794 \\
\hline & standard & 0.062 & 0.130 & 0.276 & 0.059 & 0.130 & 0.276 & 0.100 & 0.229 & 3.996 \\
\hline & $\begin{array}{l}\text { deviation } \\
\text { coefficient of } \\
\text { variation }\end{array}$ & 0.083 & 0.173 & 0.370 & 0.087 & 0.177 & 0.372 & 0.135 & 0.307 & 5.033 \\
\hline & $\%$ cases in C.I. & $98.6 \%$ & $98.9 \%$ & $98.8 \%$ & $89.7 \%$ & $99.0 \%$ & $98.9 \%$ & n.a. & n.a. & n.a. \\
\hline \multirow{4}{*}{$100 \%$} & average & 0.751 & 0.751 & 0.745 & 0.751 & 0.751 & 0.745 & 0.750 & 0.746 & 0.800 \\
\hline & standard & 0.056 & 0.129 & 0.276 & 0.056 & 0.129 & 0.276 & 0.099 & 0.229 & 4.539 \\
\hline & $\begin{array}{l}\text { deviation } \\
\text { coefficient of } \\
\text { variation }\end{array}$ & 0.075 & 0.172 & 0.370 & 0.075 & 0.172 & 0.370 & 0.132 & 0.307 & 5.674 \\
\hline & $\%$ cases in C.I. & $99.0 \%$ & $99.1 \%$ & $98.9 \%$ & $99.0 \%$ & $99.1 \%$ & $98.9 \%$ & n.a. & n.a. & n.a. \\
\hline
\end{tabular}


Panel (b): Underlying beta 1.00

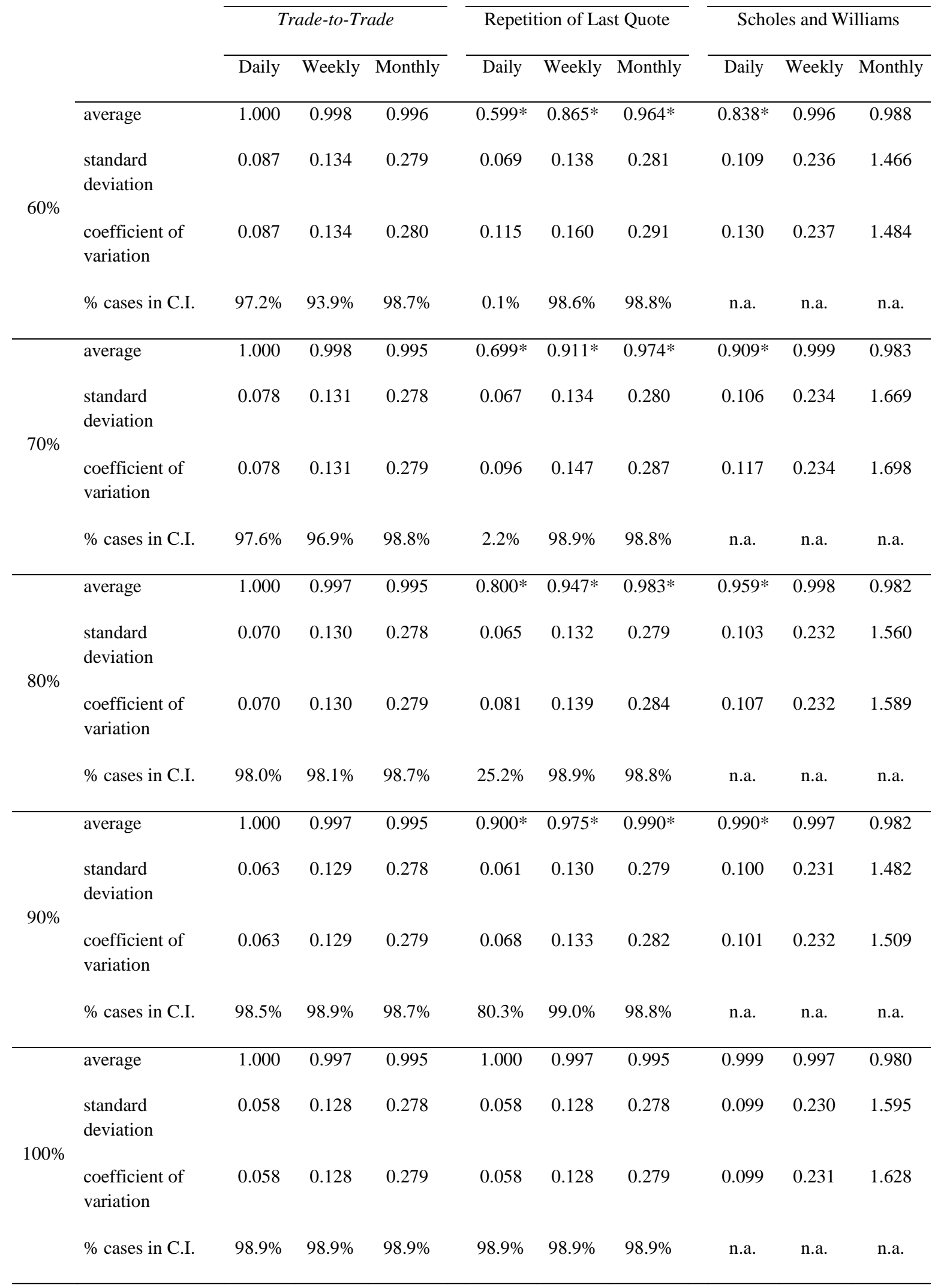




\section{Panel (c): Underlying beta 1.25}

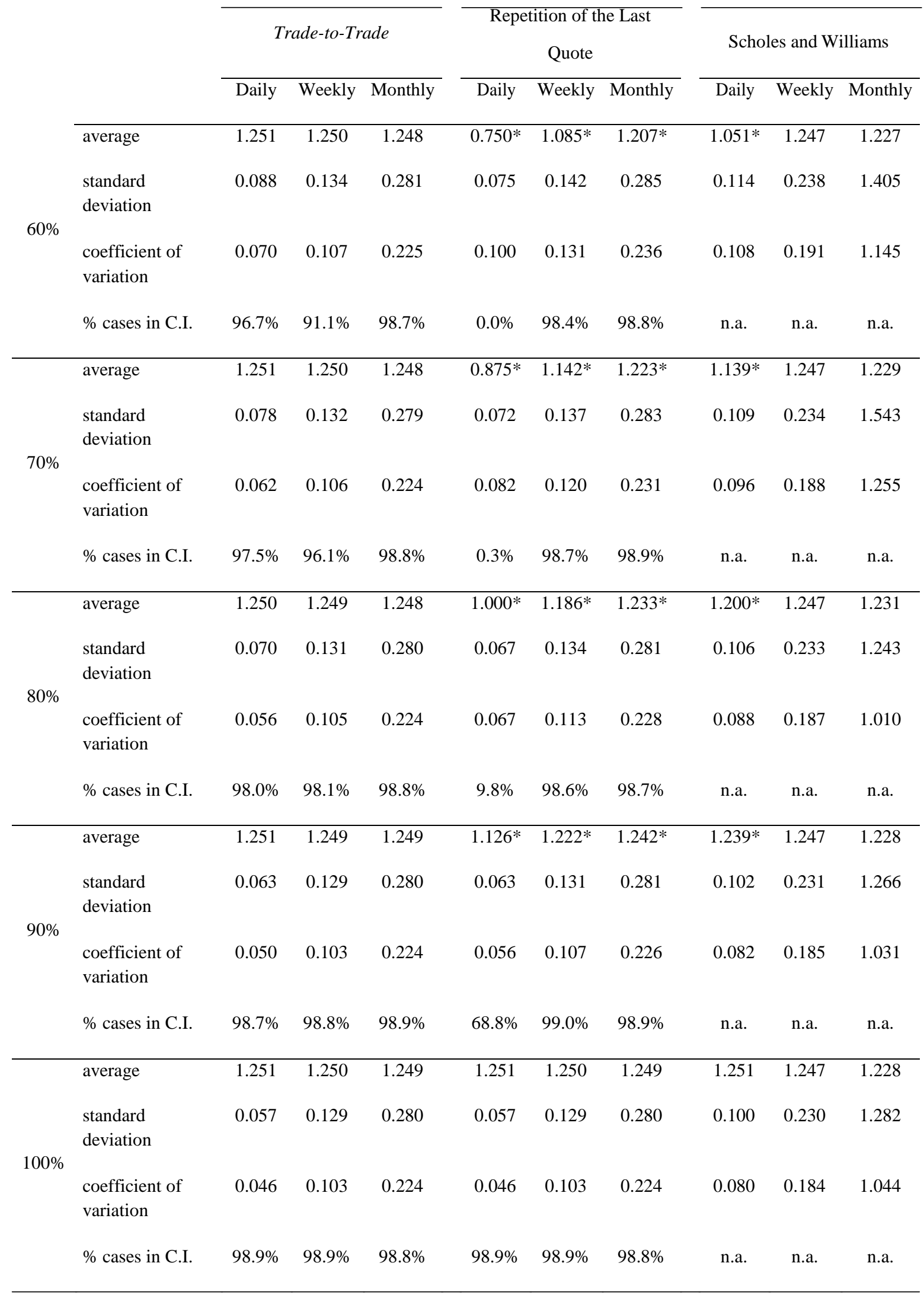


For each set of 10,000 cases of the 135 tested combinations, the average was calculated (indicated with * when the difference between the average and the underlying beta is significant at 1\%), the standard deviation and the coefficient of variation (standard deviation/average). Also, the percentage of times the underlying beta would be contained in the confidence interval of $99 \%$ of the calculated beta was verified, presented in the line $\%$ cases in C.I.. Panel (a) presents the data for the 0.75 underlying beta, panel (b) presents the data for the 1.00 underlying beta and panel (c) presents the data for the 1.25 underlying beta. The beta was calculated by the trade-to-trade method (presented in the Trade-to-Trade column), by the repetition and last quote method (presented in column Repetition of Last Quote) and by the Scholes and Williams (1977) adjustment (present in the Scholes and Williams column). Each one of these columns is subdivided according to the return periodicity considered for the beta calculation (Daily, Weekly and Monthly). The lines are grouped by the level of liquidity $(60 \%, 70 \%$, $80 \%, 90 \%$ and $100 \%$ of trading days).

Source: Prepared by the authors.

The evidence, as presented in Table 1, confirm that the averages of estimated betas from the liquid series (100\% days with trading) are not different from the underlying betas that originated the respective random series of returns from stocks in several scenarios, at the level of $1 \%$ of significance. This result is expected from the construction of the data. It is observed that, for $100 \%$ days with trading, the TT and the RUC methods are equal in operational terms, therefore, they are the same.

The results also indicate that the average of the betas from the illiquid series $(60 \%$ to $90 \%$ of days with trading) estimated by the TT method, are statistically equal to the underlying betas.

However, for the illiquid series, table 1 shows that the beta averages estimated by the RUC method are, for all periodicities, statistically different from the underlying betas, coming approximately to a $40 \%$ difference with the daily betas. It can be verified that the daily beta of the RUC method to the $60 \%$ trading days scenario is: in panel (a) of 0.450 (for an underlying beta of 0.75), on panel (b) of 0.599 (for an underlying beta of 1.00) and in panel (c) of 0.750 (for an underlying beta of 1.25). These results corroborate the bias of the illiquid stock betas.

The SW method for the illiquid series, presents all the estimated average daily betas different from the underlying beta, on the level of significance of $1 \%$, therefore biased, with differences that may reach $16 \%$. The average weekly and monthly betas are statistically the same as the underlying beta. However, it is noted that the averages of the monthly betas can be up to $8 \%$ different from the underlying beta (underlying beta of 0.75 to $70 \%$ of days with trading estimated in 0.826). It was verified, however, that the SW method was not capable to eliminate the bias for the daily periodicity.

Besides the analysis of the average of 10,000 cases, table 1 also provides information about the dispersion of betas individually estimated around this average. The standard 
deviation is especially high for estimated betas with a monthly periodicity by means of the SW method.

As for the percentage of times that an underlying beta would be contained in the confidence interval of each calculated beta, it can be verified that (a) for the daily periodicity, the RUC method presents several scenarios with less than $50 \%$ of the cases (some with less that $1 \%$ of the cases), and the TT method presents all scenarios above $95 \%$ of cases; and (b) for the weekly and monthly periodicity, both methods present all the scenarios above $95 \%$ of cases. However, it is important to point out that the RUC method produced an average of weekly beta for $60 \%$ of days with trading approximately $13 \%$ below the underlying beta, for the three beta levels.

It is observed that the lowest coefficient of variation, for all scenarios, is that of the beta estimated by the TT method, and the highest is of the beta estimated by the SW method. The coefficient of variation is, especially, high, for betas estimated by the SW method for monthly periodicity, when a high standard deviation is observed for the 10,000 cases series.

Graph 1 presents the histogram of the 10,000 cases for each one of the methods (TT, RUC and SW) and periodicities (daily, weekly and monthly), analyzed considering the lowest tested liquidity (60\% of days with trading) and underlying beta of 1.00 .

Panel (a): Daily Periodicity

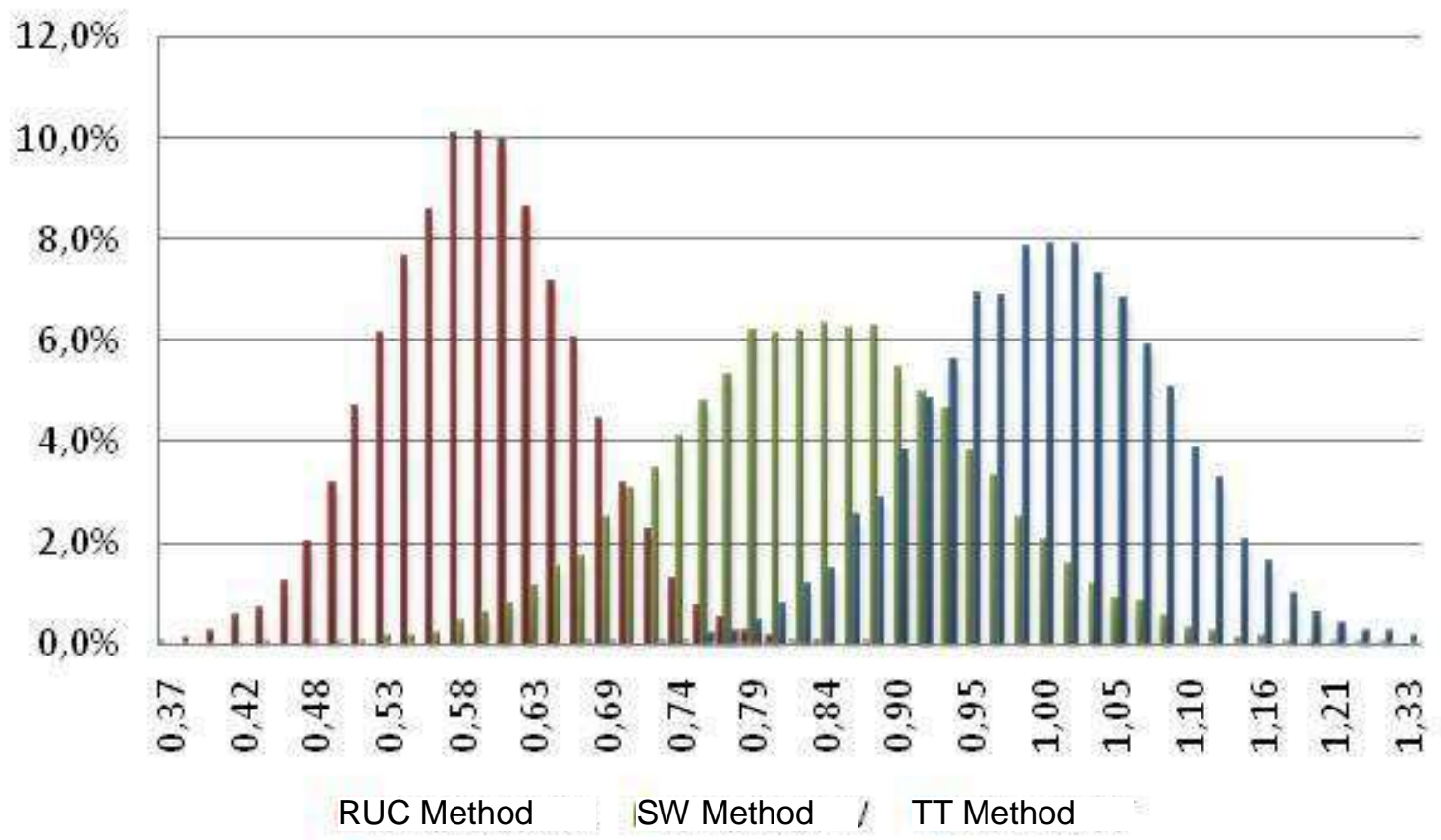


Panel (b): Weekly Periodicity

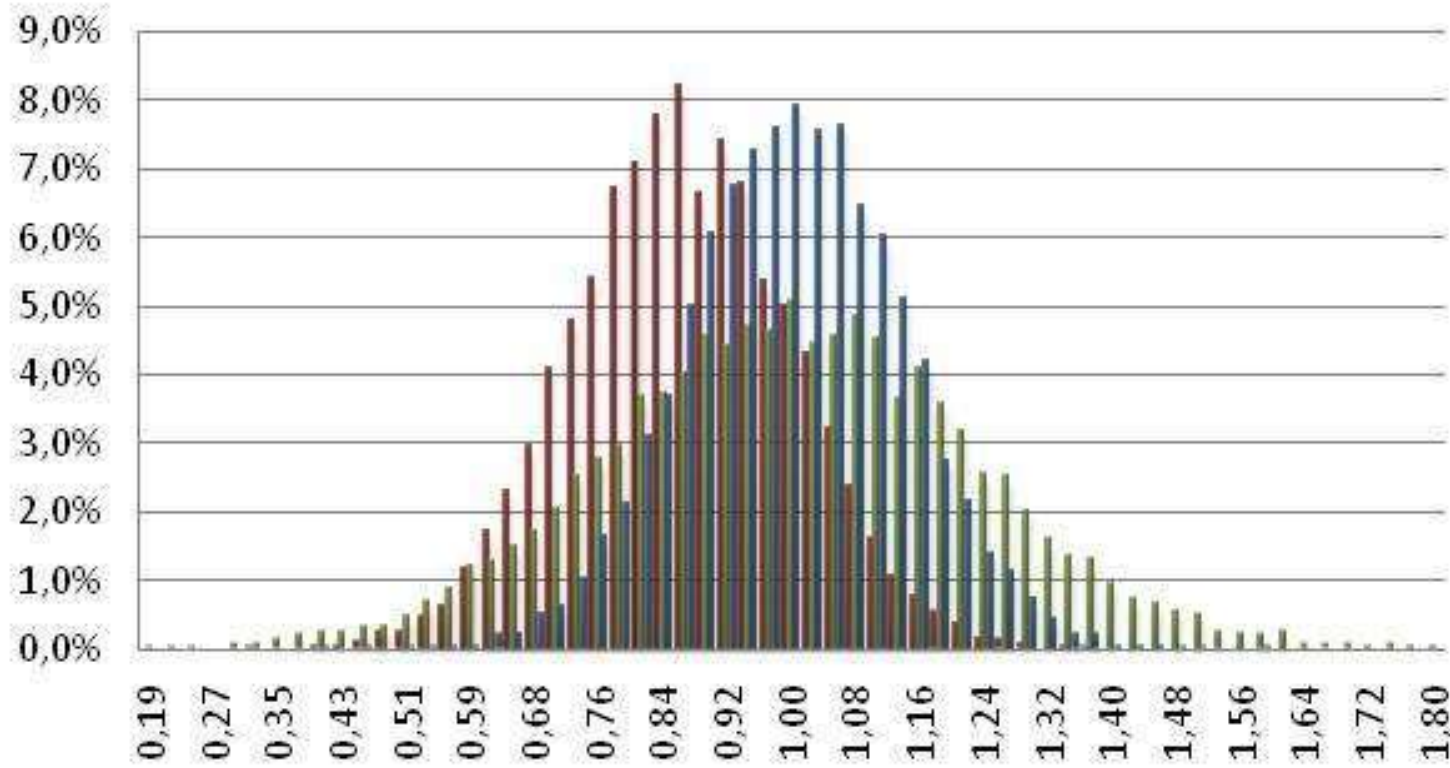

Método RUC MétodoSW Método TT

Panel (c): Monthly Periodicity

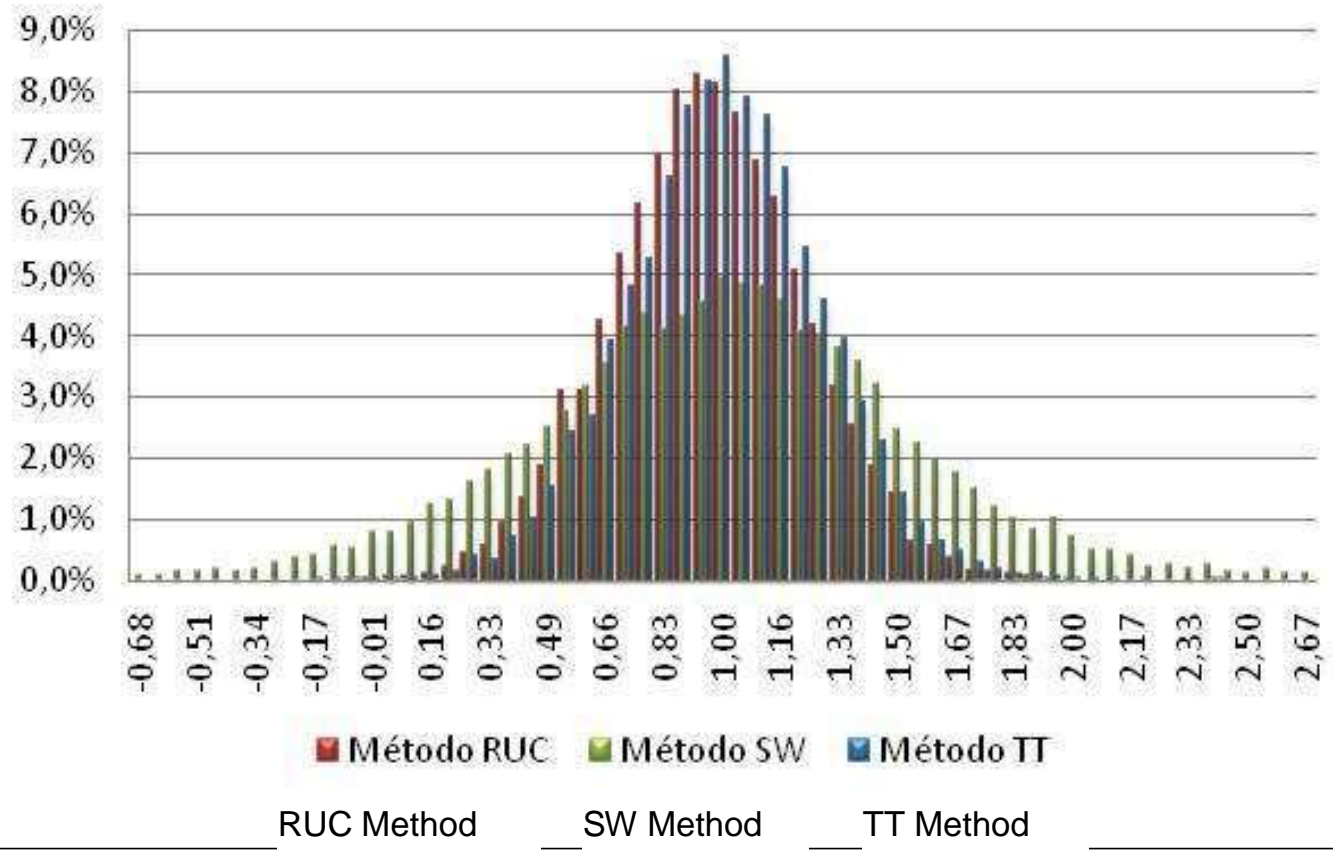

Graph 1 - Histogram - Histogram of the 10,000 estimated betas for $60 \%$ trading days and underlying beta of 1.00. Panel (a) presents the histogram for the daily periodicity and the three methods (TT, RUC and SW), panel (b) presents the histogram for the weekly periodicity and the three methods (TT, RUC and SW), and panel (c) presents the histogram for the monthly periodicity and the three methods (TT, RUC and SW). The KolmogorovSmirnov test for normality rejected the hypothesis of being normal, at $10 \%$ of significance, just for the monthly beta calculated by the SW method. Prepared by the authors. 
As was expected, from the construction of the random series, the beta distribution is, for most cases pointed out in graph 1, normal (the Kolmogorov-Smirnov test for normality rejected the hypothesis of normality, at $10 \%$ of significance, only for the distribution of the monthly betas estimated by the SW method). The histogram corroborates what had already been identified in table 1: (a) for daily periodicity, only the beta calculated by the TT method has an average equal to the underlying beta, being that the other 2 methods produce average betas biased downwards; (b) for the weekly periodicity, the TT and SW methods produce mean betas equal to the underlying beta, but the distribution of the SW beta has a wider dispersion and the RUC beta continues to be biased downwards; and (c) for the monthly periodicity, the three methods produce mean betas close to the underlying beta (the beta calculated by the RUC method is still statistically different from the underlying beta at $1 \%$ ), being that the dispersion of the SW beta is also greater than that of the other 2 methods. For the cases not presented, the average and the standard deviations can be obtained directly from table 1 .

Graph 2 presents the evolution of the beta average for the simulated 10,000 cases, in which the abscissa presents the number of cases considered in the calculation of the average (on a logarithmic scale), and the ordinates present the average for that number of cases. It was considered the lowest liquidity tested (60\% trading days) and the underlying beta at 1.00 .

Panel (a): Daily periodicity

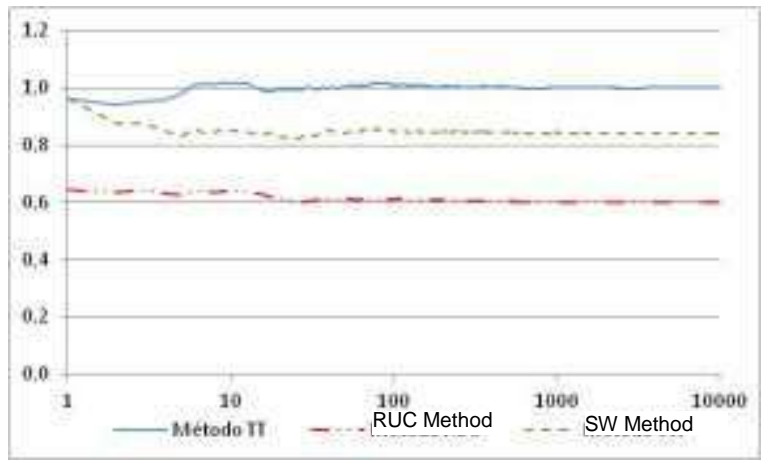

\section{Panel (b): Weekly Periodicity}

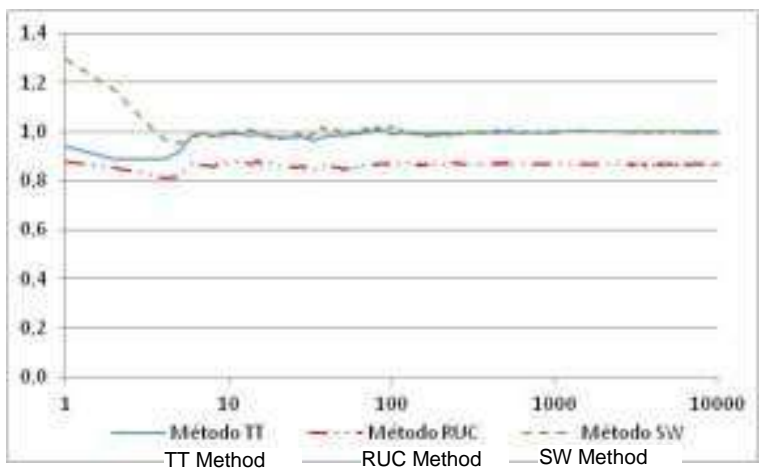




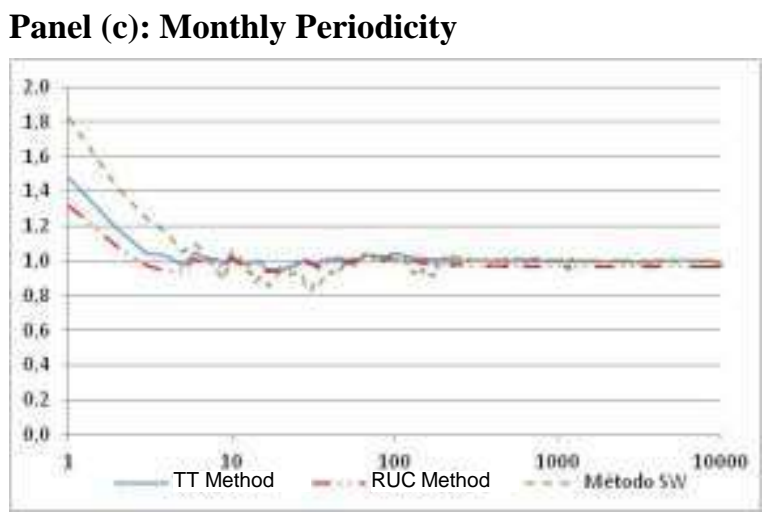

Graph 2 - Mean convergence- Graph of the evolution of the beta's average considering the 10,000 simulated cases, estimated for $60 \%$ trading days and underlying beta of 1.00. The $\mathrm{x}$ axis is on logarithmic scale. Panel (a) presents the graph for the daily periodicity and for the three methods (TT, RUC and SW), panel (b) presents the graph for the weekly periodicity and for the three methods (TT, RUC and SW), and panel (c) presents the graph for the monthly periodicity and for the three methods (TT, RUC and SW). Prepared by the authors.

It is observed in graph 2 that (a) for daily periodicity, only the beta average calculated by the TT method converges to the underlying beta, (b) for the weekly periodicity, the average of the betas estimated by the TT and SW methods converge towards the underlying beta, and (c) for the monthly periodicity, the three methods produce average betas that converge towards the underlying beta, despite the fact that the average beta calculated by the RUC method is statistically different from the underlying beta, at $1 \%$ of significance. Except for the monthly beta calculated by the SW method, the average beta stabilizes (considering its economic impact) starting at approximately 10 cases.

Another relevant discussion is that of the economic impact on the imprecision of the estimation of the betas. In table 2, the difference between the cost of equity that would be obtained with the estimated beta and the cost of equity which would be obtained from the underlying beta would be presented (considering the premises used in the simulation: risk free rate of $6.0 \%$ p.a. and market premium of $5.0 \%$ p.a.). 
Table 2 - Difference in Cost of Equity

Panel (a): Underlying beta 0.75

\begin{tabular}{|c|c|c|c|c|c|c|c|c|c|c|}
\hline & & \multirow{2}{*}{\multicolumn{3}{|c|}{ Trade-to-Trade }} & \multirow{2}{*}{\multicolumn{3}{|c|}{ Repetition of the Last Quote }} & \multirow{2}{*}{\multicolumn{3}{|c|}{ Scholes and Williams }} \\
\hline & & & & & & & & & & \\
\hline & & Daily & Weekly & Monthly & Daily & Weekly & Monthly & Daily & Weekly & Monthly \\
\hline \multirow{5}{*}{$60 \%$} & average & $0.0 \%$ & $0.0 \%$ & $0.0 \%$ & $-1.5 \%$ & $-0.5 \%$ & $-0.2 \%$ & $-0.6 \%$ & $0.0 \%$ & $0.3 \%$ \\
\hline & standard deviation & $0.4 \%$ & $0.7 \%$ & $1.4 \%$ & $0.3 \%$ & $0.7 \%$ & $1.4 \%$ & $0.5 \%$ & $1.2 \%$ & $28.2 \%$ \\
\hline & minimum & $-1.8 \%$ & $-2.6 \%$ & $-5.4 \%$ & $-2.8 \%$ & $-3.2 \%$ & $-5.4 \%$ & $-2.8 \%$ & $-4.9 \%$ & $-164.7 \%$ \\
\hline & maximum & $1.7 \%$ & $2.6 \%$ & $5.1 \%$ & $-0.2 \%$ & $2.4 \%$ & $5.4 \%$ & $1.6 \%$ & $5.4 \%$ & $2.568 \%$ \\
\hline & amplitude & $3.5 \%$ & $5.2 \%$ & $10.5 \%$ & $2.6 \%$ & $5.6 \%$ & $10.8 \%$ & $4.4 \%$ & $10.3 \%$ & $2.732 \%$ \\
\hline \multirow{5}{*}{$70 \%$} & average & $0.0 \%$ & $0.0 \%$ & $0.0 \%$ & $-1.1 \%$ & $-0.3 \%$ & $-0.1 \%$ & $-0.3 \%$ & $0.0 \%$ & $0.4 \%$ \\
\hline & standard deviation & $0.4 \%$ & $0.7 \%$ & $1.4 \%$ & $0.3 \%$ & $0.7 \%$ & $1.4 \%$ & $0.5 \%$ & $1.2 \%$ & $36.5 \%$ \\
\hline & minimum & $-1.5 \%$ & $-2.4 \%$ & $-5.3 \%$ & $-2.2 \%$ & $-2.8 \%$ & $-5.5 \%$ & $-2.3 \%$ & $-5.3 \%$ & $-150.6 \%$ \\
\hline & maximum & $1.5 \%$ & $2.4 \%$ & $6.0 \%$ & $0.2 \%$ & $2.2 \%$ & $5.7 \%$ & $1.9 \%$ & $6.4 \%$ & $3.467 \%$ \\
\hline & amplitude & $3.0 \%$ & $4.8 \%$ & $11.3 \%$ & $2.4 \%$ & $5.0 \%$ & $11.2 \%$ & $4.2 \%$ & $11.7 \%$ & $3.618 \%$ \\
\hline \multirow{5}{*}{$80 \%$} & average & $0.0 \%$ & $0.0 \%$ & $0.0 \%$ & $-0.7 \%$ & $-0.2 \%$ & $-0.1 \%$ & $-0.1 \%$ & $0.0 \%$ & $0.2 \%$ \\
\hline & standard deviation & $0.3 \%$ & $0.7 \%$ & $1.4 \%$ & $0.3 \%$ & $0.7 \%$ & $1.4 \%$ & $0.5 \%$ & $1.1 \%$ & $20.9 \%$ \\
\hline & minimum & $-1.4 \%$ & $-2.6 \%$ & $-5.3 \%$ & $-1.9 \%$ & $-2.4 \%$ & $-5.5 \%$ & $-1.9 \%$ & $-4.7 \%$ & $-165.9 \%$ \\
\hline & maximum & $1.3 \%$ & $2.7 \%$ & $5.6 \%$ & $0.3 \%$ & $2.5 \%$ & $5.7 \%$ & $2.1 \%$ & $5.1 \%$ & $1.744 \%$ \\
\hline & amplitude & $2.7 \%$ & $5.3 \%$ & $10.9 \%$ & $2.2 \%$ & $4.9 \%$ & $11.2 \%$ & $4.0 \%$ & $9.8 \%$ & $1.910 \%$ \\
\hline \multirow{5}{*}{$90 \%$} & average & $0.0 \%$ & $0.0 \%$ & $0.0 \%$ & $-0.4 \%$ & $-0.1 \%$ & $0.0 \%$ & $0.0 \%$ & $0.0 \%$ & $0.2 \%$ \\
\hline & standard deviation & $0.3 \%$ & $0.7 \%$ & $1.4 \%$ & $0.3 \%$ & $0.7 \%$ & $1.4 \%$ & $0.5 \%$ & $1.1 \%$ & $20.0 \%$ \\
\hline & minimum & $-1.3 \%$ & $-2.5 \%$ & $-5.5 \%$ & $-1.5 \%$ & $-2.4 \%$ & $-5.4 \%$ & $-1.9 \%$ & $-5.1 \%$ & $-168.6 \%$ \\
\hline & maximum & $1.2 \%$ & $2.5 \%$ & $5.6 \%$ & $0.6 \%$ & $2.4 \%$ & $5.5 \%$ & $2.3 \%$ & $4.8 \%$ & $1.628 \%$ \\
\hline & amplitude & $2.5 \%$ & $5.0 \%$ & $11.1 \%$ & $2.1 \%$ & $4.8 \%$ & $10.9 \%$ & $4.2 \%$ & $9.9 \%$ & $1.797 \%$ \\
\hline \multirow{5}{*}{$100 \%$} & average & $0.0 \%$ & $0.0 \%$ & $0.0 \%$ & $0.0 \%$ & $0.0 \%$ & $0.0 \%$ & $0.0 \%$ & $0.0 \%$ & $0.2 \%$ \\
\hline & standard deviation & $0.3 \%$ & $0.6 \%$ & $1.4 \%$ & $0.3 \%$ & $0.6 \%$ & $1.4 \%$ & $0.5 \%$ & $1.1 \%$ & $22.7 \%$ \\
\hline & minimum & $-1.2 \%$ & $-2.2 \%$ & $-5.4 \%$ & $-1.2 \%$ & $-2.2 \%$ & $-5.4 \%$ & $-1.9 \%$ & $-5.0 \%$ & $-174.2 \%$ \\
\hline & maximum & $1.2 \%$ & $2.5 \%$ & $5.5 \%$ & $1.2 \%$ & $2.5 \%$ & $5.5 \%$ & $2.1 \%$ & $5.2 \%$ & $1.965 \%$ \\
\hline & amplitude & $2.4 \%$ & $4.7 \%$ & $10.9 \%$ & $2.4 \%$ & $4.7 \%$ & $10.9 \%$ & $4.0 \%$ & $10.2 \%$ & $2.140 \%$ \\
\hline
\end{tabular}

BBR, Braz. Bus. Rev. (Engl. ed., Online) 
Panel (b): Underlying beta 1.00

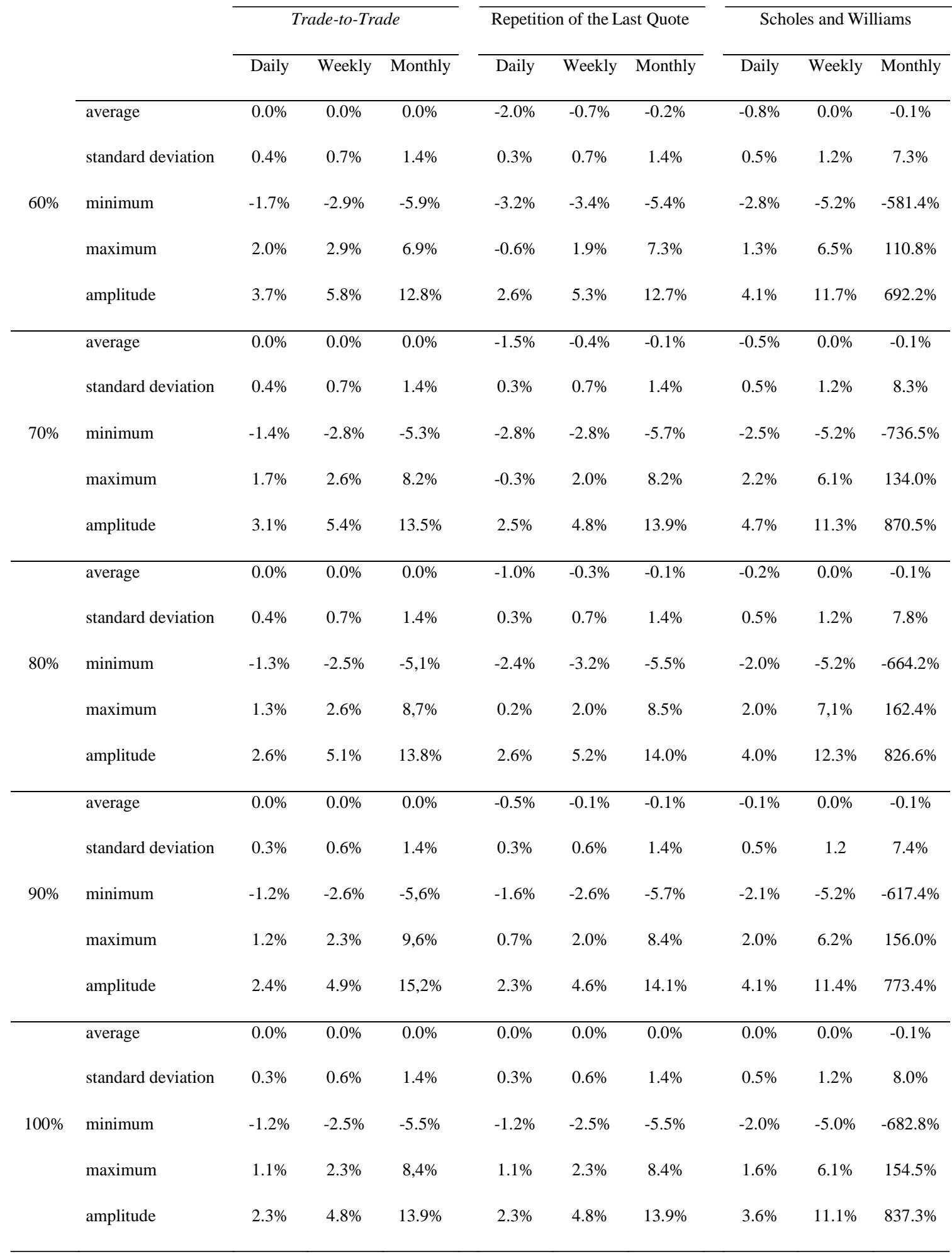

BBR, Braz. Bus. Rev. (Engl. ed., Online) 
Panel (c): Underlying beta 1.25

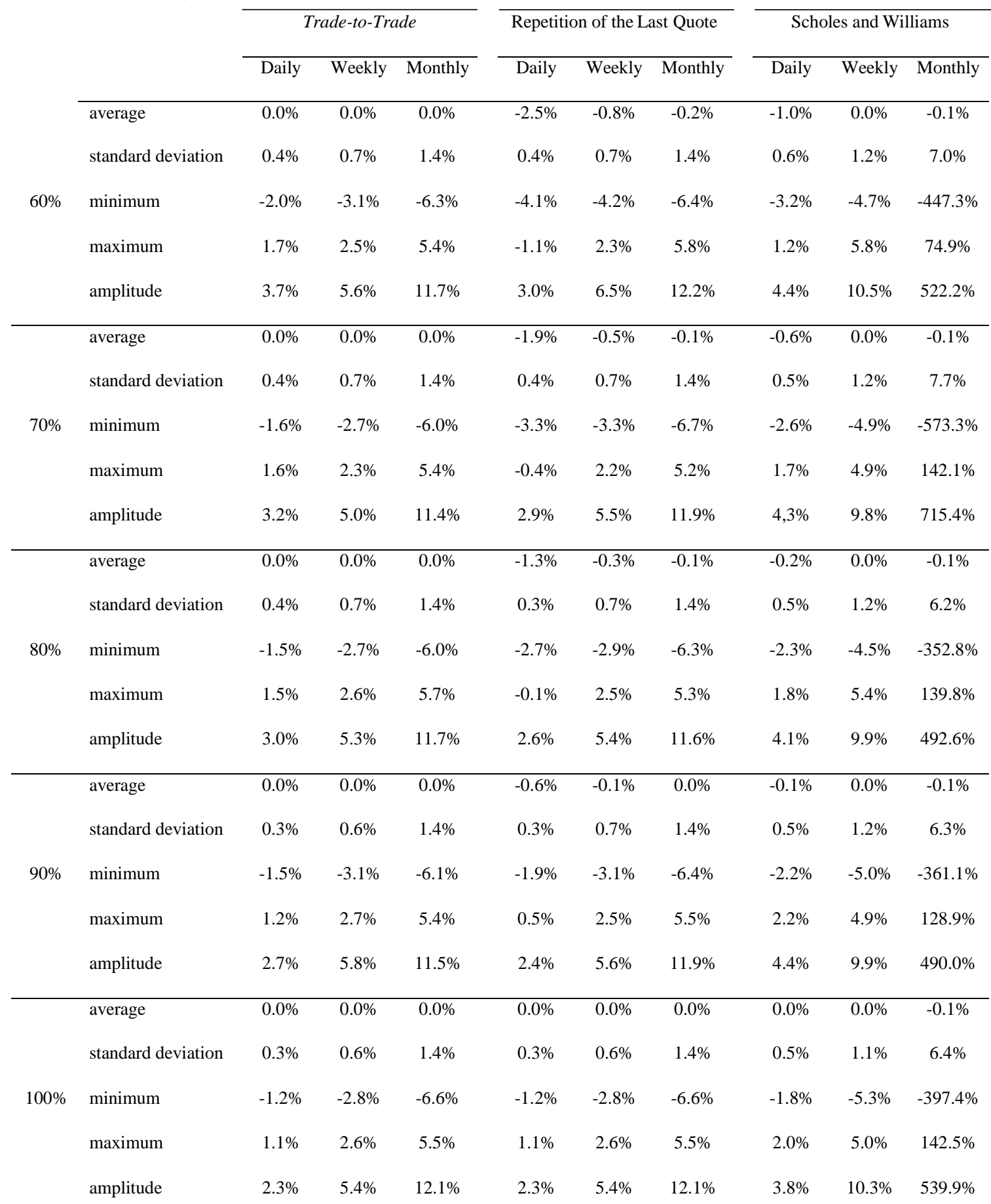

The values of the body of the table refer to the difference between the cost of equity that would be obtained with the estimated beta and the cost of the own capital that would be obtained with the underlying beta, for each one of the scenarios. The data are estimated by means of a simulation, with 10,000 cases generated for each scenario $(60 \%, 70 \%, 80 \%, 90 \%$ and $100 \%$ of trading days). The premises used in the simulation are considered: risk free rate of $6.0 \%$ p.a. and a market premium of $5.0 \%$ p.a. The columns indicate the methods (Trade-to-Trade, Repetition of the Last Quote, and Scholes and Williams) and are subdivided according to the return periodicity considered for the calculation of beta (Daily, Weekly and Monthly). The lines are grouped by the level of liquidity $(60 \%, 70 \%, 80 \%, 90 \%$ and $100 \%$ of trading days).

Source: Prepared by the authors. 
Table 2 offers two analyses: (a) the difference analysis obtained by using the average of the betas of the 10,000 cases and (b) the analysis of the individual cases by means of the minimum difference, of the maximum difference and difference amplitude.

Starting with the difference analysis obtained with the average of the 10,000 cases, it is possible to conclude that:

- The economic differences of the cost of equity for the TT method are null;

- The RUC method produces significant differences of the daily and weekly betas, of up to 2.5 percentage points less than the cost of equity that would be obtained with the underlying beta (scenario of $60 \%$ trading days, for the underlying beta at 1.25 , and the average estimated beta at 0.750 );

- The economic differences of the monthly betas estimated by the RUC method are negligible;

- The SW method produces economically negligible differences, except for daily periodicities and levels of trading days below $80 \%$.

In individual cases, it can be verified that: (a) the amplitude of the differences is smaller for the daily betas, taking into account that the standard error for daily betas is smaller than for other periodicities, consistent with Daves et. al. (2000); (b) that the smaller amplitudes are those produced by betas estimated by the RUC method. However, the betas estimated by the RUC method would not be the best alternative, having in mind that, on average, they present a cost of equity lower than that which would be obtained with the underlying beta (biased). Therefore, one must look to the difference module produced (i) by the minimum and (ii) by the maximum beta calculated by each method. This analysis indicates that the best alternative for the calculation of the cost of equity would be the beta calculated by the TT method and, more specifically, the one calculated with daily periodicity, for presenting the smallest absolute difference, minimum or maximum.

Also, the beta's confidence interval was calculated to $99 \%$ (2.58 deviations for more or for less) and later the difference in cost of equuity for the extremes of this confidence interval. Table 3 presents the maximum between (a) the module of the difference of the upper extreme and (b) the module of the difference of the inferior extreme for the three methods and for the three periodicities. 
The building of the confidence interval defined above considered that the beta distributions for the several series of 10,000 cases are normal distributions. The KolmogorovSmirnov test did not reject the hypothesis of normality at $10 \%$ for most series, except for: (a) the beta series estimated with monthly periodicity by the SW method (p value of $0 \%$ ); (b) the beta series estimated with weekly periodicity by the SW method and underlying beta of 1.25 (p value of $4.5 \%$ for $60 \%$ and $70 \%$ trading days, $2.8 \%$ for $80 \%$ trading days, $2.9 \%$ for $90 \%$ trading days and $3.5 \%$ for $100 \%$ trading days); and (c) the beta series estimated with weekly periodicity by the TT method with underlying beta 1.25 and $90 \%$ trading days (p value of $8.2 \%)$.

\section{Table 3 - Maximum Difference in Cost of Equity}

\section{Panel (a): Daily Periodicity}

\begin{tabular}{|c|c|c|c|c|c|c|c|c|c|}
\hline \multirow[b]{2}{*}{ Days with trading } & \multicolumn{3}{|c|}{ Underlying Beta 0.75} & \multicolumn{3}{|c|}{ Underlying Beta 1.00} & \multicolumn{3}{|c|}{ Underlying Beta 1.25} \\
\hline & TT & RUC & SW & TT & RUC & SW & TT & RUC & SW \\
\hline $60 \%$ & $1.12 \%$ & $2.33 \%$ & $1.95 \%$ & $1.12 \%$ & $2.90 \%$ & $2.22 \%$ & $1.14 \%$ & $3.47 \%$ & $2.47 \%$ \\
\hline $70 \%$ & $0.99 \%$ & $1.92 \%$ & $1.65 \%$ & $1.01 \%$ & $2.37 \%$ & $1.82 \%$ & $1.01 \%$ & $2.80 \%$ & $1.96 \%$ \\
\hline $80 \%$ & $0.90 \%$ & $1.53 \%$ & $1.45 \%$ & $0.90 \%$ & $1.84 \%$ & $1.53 \%$ & $0.90 \%$ & $2.11 \%$ & $1.62 \%$ \\
\hline $90 \%$ & $0.80 \%$ & $1.14 \%$ & $1.33 \%$ & $0.81 \%$ & $1.29 \%$ & $1.34 \%$ & $0.82 \%$ & $1.43 \%$ & $1.37 \%$ \\
\hline $100 \%$ & $0.73 \%$ & $0.73 \%$ & $1.28 \%$ & $0.75 \%$ & $0.75 \%$ & $1.28 \%$ & $0.74 \%$ & $0.74 \%$ & $1.30 \%$ \\
\hline
\end{tabular}

Panel (b): Weekly Periodicity

\begin{tabular}{|c|c|c|c|c|c|c|c|c|c|}
\hline \multirow[b]{2}{*}{ Days with trading } & \multicolumn{3}{|c|}{ Underlying Beta 0.75} & \multicolumn{3}{|c|}{ Underlying Beta 1.00} & \multicolumn{3}{|c|}{ Underlying Beta 1.25} \\
\hline & TT & RUC & SW & TT & RUC & SW & TT & RUC & SW \\
\hline $60 \%$ & $1.74 \%$ & $2.22 \%$ & $3.01 \%$ & $1.74 \%$ & $2.46 \%$ & $3.06 \%$ & $1.73 \%$ & $2.66 \%$ & $3.09 \%$ \\
\hline $70 \%$ & $1.69 \%$ & $2.01 \%$ & $3.01 \%$ & $1.70 \%$ & $2.17 \%$ & $3.02 \%$ & $1.70 \%$ & $2.31 \%$ & $3.03 \%$ \\
\hline $80 \%$ & $1.69 \%$ & $1.87 \%$ & $2.98 \%$ & $1.69 \%$ & $1.97 \%$ & $3.00 \%$ & $1.69 \%$ & $2.05 \%$ & $3.02 \%$ \\
\hline $90 \%$ & $1.68 \%$ & $1.75 \%$ & $2.97 \%$ & $1.68 \%$ & $1.80 \%$ & $2.99 \%$ & $1.67 \%$ & $1.83 \%$ & $2.99 \%$ \\
\hline $100 \%$ & $1.67 \%$ & $1.67 \%$ & $2.97 \%$ & $1.67 \%$ & $1.67 \%$ & $2.98 \%$ & $1.66 \%$ & $1.66 \%$ & $2.98 \%$ \\
\hline
\end{tabular}


Panel (c): Monthly Periodicity

\begin{tabular}{|c|c|c|c|c|c|c|c|c|c|}
\hline \multirow[b]{2}{*}{ Days with trading } & \multicolumn{3}{|c|}{ Underlying Beta 0.75} & \multicolumn{3}{|c|}{ Underlying Beta 1.00} & \multicolumn{3}{|c|}{ Underlying Beta 1.25} \\
\hline & TT & RUC & SW & TT & RUC & SW & TT & RUC & SW \\
\hline $60 \%$ & $3.59 \%$ & $3.75 \%$ & $72.96 \%$ & $3.62 \%$ & $3.80 \%$ & $18.97 \%$ & $3.63 \%$ & $3.89 \%$ & $18.24 \%$ \\
\hline $70 \%$ & $3.57 \%$ & $3.67 \%$ & $94.54 \%$ & $3.61 \%$ & $3.74 \%$ & $21.62 \%$ & $3.61 \%$ & $3.79 \%$ & $20.01 \%$ \\
\hline $80 \%$ & $3.59 \%$ & $3.65 \%$ & $54.07 \%$ & $3.61 \%$ & $3.68 \%$ & $20.21 \%$ & $3.62 \%$ & $3.71 \%$ & $16.13 \%$ \\
\hline $90 \%$ & $3.59 \%$ & $3.61 \%$ & $51.77 \%$ & $3.61 \%$ & $3.65 \%$ & $19.21 \%$ & $3.62 \%$ & $3.66 \%$ & $16.44 \%$ \\
\hline $100 \%$ & $3.59 \%$ & $3.59 \%$ & $58.80 \%$ & $3.61 \%$ & $3.61 \%$ & $20.68 \%$ & $3.62 \%$ & $3.62 \%$ & $16.65 \%$ \\
\hline
\end{tabular}

With the extremes of the confidence interval of $99 \%$ of the estimated beta (2.58 deviations for more or less), were calculated the cost of equity and the differences between these capital costs and what would be obtained using the corresponding underlying beta (minimum and maximum difference). Then, the maximum was obtained between (a) the minimum difference module and (b) the maximum difference module, presented in the table. The premises used in the simulation are considered: risk free rate of $6.0 \%$ p.a. and a market premium of $5.0 \%$ p.a. Panel (a) presents the data for the betas estimated with daily periodicity, panel (b) presents the data for the betas estimated with weekly periodicity, and panel (c) presents the data for the betas estimated with monthly periodicity. The columns indicate the underlying betas $0.75,1.00$ and 1.25) and are subdivided according to the method considered for the calculation of beta (TT: Trade-to-Trade, RUC - repetition of the last quote and SW Scholes and Williams). The lines are grouped by the level of liquidity $(60 \%, 70 \%, 80 \%, 90 \%$ and $100 \%$ trading days).

Source: Prepared by the authors.

It is observed, in table 3, that the TT method was capable of producing the smallest difference in cost of equity for all the analyzed scenarios, being smaller for betas estimated with daily periodicity. Taking as a basis the beta calculated with a daily periodicity, the difference produced by the TT method is always lower than $1.15 \%$, being that the RUC method would produce the maximum difference of approximately $3.50 \%$ and the SW method would produce the maximum difference of approximately $2.50 \%$. The analyses, considering that the distribution of random errors (from the market return and the asset return) is a $t$ distribution with 10 degrees of freedom ("broad tail sensibility") to simulate the broad tail of the returns, are similar to the analyses discussed above (except for the fact that the average of monthly betas estimated by the RUC method are not statistically different from the underlying beta, at $1 \%$ of significance, in one scenario: $90 \%$ trading days and underlying beta at 1.00). Therefore, they will not be presented. The same can be said for the analyses, considering that the returns of the assets were obtained by means of an alternative procedure ("alternative procedure sensitivity"): calculating the first random number used to attribute to each day the existence or not of trading and, after that, calculating the return for the accumulated periods between days with trading - being that every accumulated return calculated on the geometric mean return of the market during the period of days without negotiation (calculated multiplying the daily random error, accepted in this work by the root of the number of days in 
the period without trading). The appendix presents table 3 to the "broad tail sensitivity" (table 3A), and for the "alternative procedure sensitivity" (table 3B).

\section{FINAL CONSIDERATIONS}

The beta is one of the most important parameters in finance. For this reason, its calculation has been widely studied. Since the true beta is not known, this paper decided in favor of a simulation, which allows the comparison of the estimated beta with the underlying beta, known a priori. One should note that the simulated market index, in this simulation, is completely efficient. By means of the simulation, 3 methods of calculation were studied repetition of last quote (RUC), trade-to-trade (TT) and adjustment by Scholes and Williams (1977)(SW) - and three periodicities of return (daily, weekly and monthly), for the 5 levels of trading days: $60 \%, 70 \%, 80 \%, 90 \%$ and $100 \%$ and three levels of beta: $0.75,1.00$ and 1.25 .

The result clearly shows that the TT method is superior to the RUC and SW methods for estimation of the beta for stocks that aren't traded every day. This method, although little used, is the only one capable of correctly estimating the beta calculated with the periodicity of daily, weekly or monthly return. It must be used preferentially with daily periodicity, for it presents the smallest error of estimation, which produces smaller distortions in the cost of capital. The distortion in the cost of capital produced by betas estimated with a monthly periodicity double in regards to that produced by betas estimated with a weekly periodicity, which by its turn can also, in some cases, double in relation to that produced by betas estimated with daily periodicity.

The SW method did not eliminate the problem of the downwards bias, when calculated with a daily periodicity, but did not present, for the average beta, a significant bias with weekly and monthly periodicity. The large dispersion of the individual estimates renders this method unreliable when applied to small numbers of stocks. This dispersion can result in serious mistakes in the estimation of the cost of capital and, consequently, in the value of the companies, in the investment decision, in the market efficiency tests and the definition of public service tariffs.

This result is in line with that obtained by Bowie and Bradfield (1993), which, simulating monthly returns for the non-liquid series, show that the TT method produces a beta estimator superior to that obtained by the method of Cohen et. al. (1983), which is considered by the authors as a more general method of which the Scholes and Williams (1977) and Dimson methods (1979) are special cases. 
The RUC method, more traditional and available in information systems, proved to be clearly and severely inconsistent, being biased when calculated with daily and weekly periodicity. Although the error in estimation is economically close to that produced by the TT method, the downward bias makes it unreliable in the application to portfolios with small numbers of stocks, in the estimation of the cost of capital and the resulting applications. For a monthly periodicity, when the downward bias becomes not economically significant, the method proves to be comparable to the TT method for the same periodicity.

Future studies may empirically study what was studied here by means of simulations.

\section{REFERENCES}

BARTHOLDY, J.; RIDING, A. Thin trading and the estimation of betas: the efficacy of alternative techniques. The Journal of Financial Research, v. 17, n. 2, p. 241-254, 1994.

BODIE, Z.; KANE, A.; MARCUS, A. J. Fundamentos de investimentos. 3. ed. Porto Alegre: Bookman, 2000.

BOWIE, D. C.; BRADFIELD, D. J. Improved beta estimation on the Johannesburg stock exchange: a simulation study. South African Journal of Business Management, v. 24, n. 4, p. 118-123, 1993.

BROOKS, C. Introductory econometrics for finance. 2. ed. Cambridge, UK: University Press, 2008.

COHEN, K. J. et al. Friction in the trading process and the estimation of systematic risk. Journal of Financial Economics, v. 12, p. 263-278, 1983.

COPELAND, T.; KOLLER, T.; MURRIN, J. Avaliação de empresas: valuation: calculando e gerenciando o valor das empresas. 3. ed. São Paulo: Pearson, 2002.

COPELAND, T; WESTON, J. F.; SHASTRI, K. Financial Theory and Corporate Policy.4. ed. Boston: Pearson, Boston, 2005.

DAMODARAN, A. Damodaran on valuation: security analysis for investment and corporate finance. New York: John Wiley \& Sons, 1994.

DAMODARAN, A. Corporate Finance: theory and practice. New York: John Wiley \& Sons, 1997.

DAVES, P. R.; EHRHARDT, M. C.; KUNKEL, R. A. Estimating systematic risk: the choice of return interval and estimation period. Journal of Financial and Strategic Decisions, v. 13, n. 1, p. 7-13, 2000.

DIMSON, E. Risk measurement when shares are subject to infrequent trading. Journal of Financial Economics, v. 7, n. 2, p. 197-226, 1979.

DIMSON, E.; MARSH, P. The stability of UK risk measures and the problem of thin-trading. Journal of Finance, v. 38, n. 3, p.753-783, 1983. 
FOWLER, D. J.; RORKE, C. H. Risk measurement when shares are subject to infrequent trading. Journal of Financial Economics, v. 12, n. 2, p. 279-283, 1983.

HANDA, P.; KOTHARI, S. P.; WASLEY, C. The relation between the return interval and betas implication for size effect. Journal of Financial Economics, v. 23, n. 1, p. 70-100, 1989.

HAWAWINI, G. Why beta shifts as the return interval changes. Financial Analysts Journal, v. 39, n. 3, p. 73-77, 1983.

MARSH, P. Equity rights issues and the efficiency of the UK stock market. Journal of Finance, v. 34, n. 4, p. 839-862, 1979.

MAYNES, E.; RUMSEY, J. Conducting event studies with thinly traded stocks. Journal of Banking and Finance, v. 17, n. 1, p. 145-157, 1993.

KOLLER, T.; GOEDHART, M. H.; WESSELS, D. Valuation: measuring and managing the value of companies. 4. ed. New Jersey: John Wiley \& Sons, 2005.

SCHOLES, M.; WILLIAMS, J. Estimating betas from nonsynchronous data. Journal of Financial Economics, v. 5, n. 3, p. 309-327, 1977.

STAMBAUGH, R. F. On the exclusion of assets from tests of the two-parameter model: a sensitivity analysis. Journal of Financial Economics, v. 10, n. 3, p. 237-268, 1982.

\section{APPENDIX}

Presentation of table 3, in which the calculation is made based on the "broad tail sensitivity", when it is assumed that the error distribution is a t distribution with 10 degrees of freedom, and based on the "alternative procedure sensitivity", when prices are simulated only for the days when there was trading. 
Table 3A - Appendix Broad Tail Sensitivity - Similar to table 3, but calculated for the "broad tail sensitivity". Prepared by the authors.

\section{Panel (a): Daily Periodicity}

\begin{tabular}{|c|c|c|c|c|c|c|c|c|c|}
\hline \multirow[b]{2}{*}{ Days with trading } & \multicolumn{3}{|c|}{ Underlying Beta 0.75} & \multicolumn{3}{|c|}{ Underlying Beta 1.00} & \multicolumn{3}{|c|}{ Underlying Beta 1.25} \\
\hline & TT & RUC & SW & TT & RUC & SW & TT & RUC & SW \\
\hline $60 \%$ & $1.13 \%$ & $2.34 \%$ & $1.96 \%$ & $1.13 \%$ & $2.91 \%$ & $2.21 \%$ & $1.14 \%$ & $3.52 \%$ & $2.50 \%$ \\
\hline $70 \%$ & $1.01 \%$ & $1.95 \%$ & $1.68 \%$ & $1.00 \%$ & $2.40 \%$ & $1.83 \%$ & $0.99 \%$ & $2.84 \%$ & $1.99 \%$ \\
\hline $80 \%$ & $0.92 \%$ & $1.55 \%$ & $1.47 \%$ & $0.90 \%$ & $1.85 \%$ & $1.54 \%$ & $0.90 \%$ & $2.17 \%$ & $1.60 \%$ \\
\hline $90 \%$ & $0.83 \%$ & $1.16 \%$ & $1.36 \%$ & $0.82 \%$ & $1.30 \%$ & $1.36 \%$ & $0.81 \%$ & $1.47 \%$ & $1.38 \%$ \\
\hline $100 \%$ & $0.74 \%$ & $0.74 \%$ & $1.30 \%$ & $0.74 \%$ & $0.74 \%$ & $1.30 \%$ & $0.74 \%$ & $0.74 \%$ & $1.28 \%$ \\
\hline
\end{tabular}

\section{Panel (b): Weekly Periodicity}

\begin{tabular}{|c|c|c|c|c|c|c|c|c|c|}
\hline \multirow[b]{2}{*}{ Days with trading } & \multicolumn{3}{|c|}{ Underlying Beta 0.75} & \multicolumn{3}{|c|}{ Underlying Beta 1.00} & \multicolumn{3}{|c|}{ Underlying Beta 1.25} \\
\hline & TT & RUC & SW & TT & RUC & SW & TT & RUC & SW \\
\hline $60 \%$ & $1.75 \%$ & $2.23 \%$ & $3.07 \%$ & $1.76 \%$ & $2.42 \%$ & $3.02 \%$ & $1.76 \%$ & $2.67 \%$ & $3.08 \%$ \\
\hline $70 \%$ & $1.72 \%$ & $2.04 \%$ & $3.03 \%$ & $1.72 \%$ & $2.18 \%$ & $3.02 \%$ & $1.72 \%$ & $2.34 \%$ & $3.06 \%$ \\
\hline $80 \%$ & $1.71 \%$ & $1.88 \%$ & $3.04 \%$ & $1.69 \%$ & $1.96 \%$ & $2.99 \%$ & $1.71 \%$ & $2.05 \%$ & $3.03 \%$ \\
\hline $90 \%$ & $1.69 \%$ & $1.77 \%$ & $3.02 \%$ & $1.69 \%$ & $1.81 \%$ & $2.97 \%$ & $1.69 \%$ & $1.84 \%$ & $3.01 \%$ \\
\hline $100 \%$ & $1.69 \%$ & $1.69 \%$ & $3.02 \%$ & $1.67 \%$ & $1.67 \%$ & $2.96 \%$ & $1.68 \%$ & $1.68 \%$ & $3.00 \%$ \\
\hline
\end{tabular}


Panel (c): Monthly Periodicity

\begin{tabular}{|c|c|c|c|c|c|c|c|c|c|}
\hline \multirow[b]{2}{*}{ Days with trading } & \multicolumn{3}{|c|}{ Underlying Beta 0.75} & \multicolumn{3}{|c|}{ Underlying Beta 1.00} & \multicolumn{3}{|c|}{ Underlying Beta 1.25} \\
\hline & TT & RUC & SW & TT & RUC & SW & TT & RUC & SW \\
\hline $60 \%$ & $3.60 \%$ & $3.73 \%$ & $10.76 \%$ & $3.55 \%$ & $3.76 \%$ & $55.85 \%$ & $3.65 \%$ & $3.94 \%$ & $14.87 \%$ \\
\hline $70 \%$ & $3.59 \%$ & $3.69 \%$ & $10.85 \%$ & $3.54 \%$ & $3.67 \%$ & $51.44 \%$ & $3.66 \%$ & $3.83 \%$ & $14.02 \%$ \\
\hline $80 \%$ & $3.59 \%$ & $3.64 \%$ & $10.99 \%$ & $3.55 \%$ & $3.62 \%$ & $54.64 \%$ & $3.67 \%$ & $3.76 \%$ & $13.92 \%$ \\
\hline $90 \%$ & $3.59 \%$ & $3.63 \%$ & $10.66 \%$ & $3.55 \%$ & $3.57 \%$ & $52.76 \%$ & $3.66 \%$ & $3.70 \%$ & $13.37 \%$ \\
\hline $100 \%$ & $3.59 \%$ & $3.59 \%$ & $10.79 \%$ & $3.55 \%$ & $3.55 \%$ & $50.54 \%$ & $3.67 \%$ & $3.67 \%$ & $14.50 \%$ \\
\hline
\end{tabular}

The building of the confidence interval in table $3 \mathrm{~A}$ considered that the beta distributions for the several series of 10,000 cases are normal distributions. The Kolmogorov-Smirnov test did not reject the hypothesis of normality at $10 \%$ for most series, except for: (a) the beta series estimated with monthly periodicity by the SW method (p value of $0 \%$ ); (b) the beta series estimated with monthly periodicity by the RUC method and underlying beta of 0.75 and $60 \%$ trading days ( $\mathrm{p}$ value of $7.5 \%$ ); (c) the beta series estimated with monthly periodicity by the TT method with underlying beta 1.00 and $70 \%$ trading days (p value of $7.2 \%$ ); and (d) the beta series estimated with monthly periodicity by the TT method with underlying beta of 1.25 and $90 \%$ trading days ( $\mathrm{p}$ value of $9.6 \%$ ).

Table 3B - Appendix Alternative Procedure Sensitivity - Similar to table 3, but calculated for the "alternative procedure sensitivity". Prepared by the authors.

Panel (a): Daily Periodicity

\begin{tabular}{|c|c|c|c|c|c|c|c|c|c|}
\hline \multirow[b]{2}{*}{ Days with trading } & \multicolumn{3}{|c|}{ Underlying Beta 0.75} & \multicolumn{3}{|c|}{ Underlying Beta 1.00} & \multicolumn{3}{|c|}{ Underlying Beta 1.25} \\
\hline & TT & RUC & SW & TT & RUC & SW & TT & RUC & SW \\
\hline $60 \%$ & $1.12 \%$ & $2.34 \%$ & $1.97 \%$ & $1.13 \%$ & $2.89 \%$ & $2.21 \%$ & $1.11 \%$ & $3.47 \%$ & $2.44 \%$ \\
\hline $70 \%$ & $1.02 \%$ & $1.93 \%$ & $1.67 \%$ & $1.01 \%$ & $2.36 \%$ & $1.78 \%$ & $1.02 \%$ & $2.79 \%$ & $1.97 \%$ \\
\hline $80 \%$ & $0.91 \%$ & $1.54 \%$ & $1.46 \%$ & $0.91 \%$ & $1.84 \%$ & $1.53 \%$ & $0.89 \%$ & $2.11 \%$ & $1.60 \%$ \\
\hline $90 \%$ & $0.82 \%$ & $1.14 \%$ & $1.32 \%$ & $0.80 \%$ & $1.27 \%$ & $1.35 \%$ & $0.82 \%$ & $1.45 \%$ & $1.38 \%$ \\
\hline $100 \%$ & $0.74 \%$ & $0.74 \%$ & $1.27 \%$ & $0.74 \%$ & $0.74 \%$ & $1.30 \%$ & $0.74 \%$ & $0.74 \%$ & $1.30 \%$ \\
\hline
\end{tabular}


Panel (b): Weekly Periodicity

\begin{tabular}{|c|c|c|c|c|c|c|c|c|c|}
\hline \multirow[b]{2}{*}{ Days with trading } & \multicolumn{3}{|c|}{ Underlying Beta 0.75} & \multicolumn{3}{|c|}{ Underlying Beta 1.00} & \multicolumn{3}{|c|}{ Underlying Beta 1.25} \\
\hline & TT & RUC & SW & TT & $\overline{\text { RUC }}$ & SW & TT & RUC & SW \\
\hline $60 \%$ & $1.74 \%$ & $2.24 \%$ & $3.02 \%$ & $1.73 \%$ & $2.43 \%$ & $3.04 \%$ & $1.72 \%$ & $2.64 \%$ & $3.02 \%$ \\
\hline $70 \%$ & $1.69 \%$ & $2.01 \%$ & $2.98 \%$ & $1.73 \%$ & $2.16 \%$ & $3.06 \%$ & $1.69 \%$ & $2.32 \%$ & $3.07 \%$ \\
\hline $80 \%$ & $1.69 \%$ & $1.87 \%$ & $2.98 \%$ & $1.71 \%$ & $1.96 \%$ & $2.98 \%$ & $1.68 \%$ & $2.04 \%$ & $3.03 \%$ \\
\hline $90 \%$ & $1.68 \%$ & $1.76 \%$ & $2.99 \%$ & $1.66 \%$ & $1.78 \%$ & $3.00 \%$ & $1.69 \%$ & $1.82 \%$ & $2.97 \%$ \\
\hline $100 \%$ & $1.63 \%$ & $1.63 \%$ & $2.96 \%$ & $1.67 \%$ & $1.67 \%$ & $2.99 \%$ & $1.66 \%$ & $1.66 \%$ & $3.04 \%$ \\
\hline
\end{tabular}

Panel (c): Monthly Periodicity

\begin{tabular}{|c|c|c|c|c|c|c|c|c|c|}
\hline \multirow[b]{3}{*}{ Days with trading } & \multirow{2}{*}{\multicolumn{3}{|c|}{ Underlying Beta 0.75}} & \multirow{2}{*}{\multicolumn{3}{|c|}{ Underlying Beta 1.00}} & \multirow{2}{*}{\multicolumn{3}{|c|}{ Underlying Beta 1.25}} \\
\hline & & & & & & & & & \\
\hline & TT & RUC & SW & TT & RUC & SW & TT & RUC & SW \\
\hline $60 \%$ & $3.63 \%$ & $3.76 \%$ & $11.06 \%$ & $3.57 \%$ & $3.78 \%$ & $11.87 \%$ & $3.63 \%$ & $3.87 \%$ & $423.20 \%$ \\
\hline $70 \%$ & $3.55 \%$ & $3.65 \%$ & $104.34 \%$ & $3.56 \%$ & $3.65 \%$ & $9.65 \%$ & $3.67 \%$ & $3.84 \%$ & $23.40 \%$ \\
\hline $80 \%$ & $3.58 \%$ & $3.63 \%$ & $572.24 \%$ & $3.59 \%$ & $3.66 \%$ & $13.14 \%$ & $3.60 \%$ & $3.71 \%$ & $15.07 \%$ \\
\hline $90 \%$ & $3.55 \%$ & $3.59 \%$ & $39.29 \%$ & $3.61 \%$ & $3.66 \%$ & $10.48 \%$ & $3.61 \%$ & $3.61 \%$ & $10.95 \%$ \\
\hline $100 \%$ & $3.56 \%$ & $3.56 \%$ & $8.37 \%$ & $3.62 \%$ & $3.62 \%$ & $18.10 \%$ & $3.58 \%$ & $3.58 \%$ & $39.27 \%$ \\
\hline
\end{tabular}

The building of the confidence interval in table $3 \mathrm{~B}$ considered that the beta distributions for the several series of 10,000 cases are normal distributions. The Kolmogorov-Smirnov test did not reject the hypothesis of normality at $10 \%$ for most series, except for: (a) the beta series estimated with monthly periodicity by the SW method (p value of $0 \%$ ); (b) the beta series estimated with daily periodicity by the SW method and underlying beta of 0.75 and $70 \%$ of days with trading (p value of 6.9\%); (c) the beta series estimated with monthly periodicity by the TT method with underlying beta 1.25 and $80 \%$ trading days (p value of $3.0 \%$ ); (d) the beta series estimated with monthly periodicity by the RUC method with underlying beta 1.25 and $80 \%$ trading days (p value of $5.4 \%$ ); and (e) the beta series estimated with monthly periodicity by the TT method with underlying beta of 1.25 and $90 \%$ trading days (p value of $9.2 \%$ ). 